\title{
To Study Strength Characteristics of Concrete with Rice Husk Ash
}

\author{
Paramveer Singh ${ }^{1 *}$, Tarunbir Singh ${ }^{2}$ and Gurpreet Singh ${ }^{1}$ \\ 'School of Civil Engineering, Lovely Professional University, Phagwara - 144411, Punjab, India; \\ param.1989@yahoo.com,gurpreet.18634@lpu.co.in \\ 2Department of Civil Engineering, Guru Teg Bahadur Khalsa Institute of Engineering and Technology, \\ Malaut -152107, Punjab, India; tarunbir1988@gmail.com
}

\begin{abstract}
Background/Objective: The research was carried out to study the mechanical properties of concrete by partial replacement of cement with rice husk ash. The M40 grade of concrete was used to examine compressive strength, split tensile strength and flexure strength after 7 days and 28 days of curing. The cement is to be replaced (by weight) with rice husk ash by 5\%,10\%,15\% and 20\% to get optimized results. Methods/Statistical Analysis: In this research work, emphasis was made on examining the optimized quantity of RHA used as replacement with cement (by weight) by the medium of experimental investigation. Findings: As per results, Compressive strength for $5 \%$ replacement i.e. M-RHA5 increased by $2.1 \%$ as compared with control mix and for $10 \%$ replacement i.e. M-RHA10 decreased by $1.4 \%$ as compared with control mix and it decreases for M-RHA15 and M-RHA20 mixes by $14.6 \%$ and $28.8 \%$ respectively i.e. compressive strength increases up to $10 \%$ for rice husk ash replacement with cement for M40 grade of concrete. Similarly split tensile strength also increases after $5 \%$ replacement for M-RHA5 i.e. increased by $3.9 \%$ and after $10 \%$ replacement it decrease by $17.5 \%$ and further decreasing for $15 \%$ and $20 \%$ replacement by $19.3 \%$ and $31.7 \%$ respectively as compared with RHA. There is no significant effect on split tensile strength as only $5 \%$ replacement is coming optimum. Flexural strength is optimized for different percentage of RHA and compared with control mix, i.e. it is increased by $10.9 \%$ for M-RHA5 mix and then start decreasing for M-RHA10 by 3\% as compared with control mix. So for compressive strength M-RHA10 is optimum and split tensile strength and for flexural strength optimum content for RHA in cement 5\% i.e. M-RHA5. Application/ Improvement: As RHA has significant role in increase of compressive strength as compared with split tensile strength and flexure strength. Cement replacement with RHA will help to reduce cost of construction.
\end{abstract}

Keywords: Cement replacement, Mechanical Properties, Rice Husk Ash (RHA)

\section{Introduction}

In present, concrete is used for construction widely, and main aim is to decrease the cost of construction. To overcome the cost of concrete various materials are replaced with concrete ingredients and waste materials are widely used to optimize the concrete cost. In present study, RHA is replaced with cement partially to visualize the mechanical properties of concrete and to reduce the cost of construction. RHA is widely used as supplementary cementious material to increase the strength of concrete. Rice husk ash is waste material i.e. residue of rice during their creation. In present time there is boost to use waste material to innovate new materials to strengthen the product. Similarly, Rice husk ash is used at various places for making new products by their low cost. Rice husk has burnt into ash to get their physical

${ }^{*}$ Author for correspondence 
and chemical properties to be used as mineral admixture in concrete. Pozzolanic activity of (RHA) rest on silica content, silica crystallization phase, size and surface area of RHA particles ${ }^{1}$. The most common use of RHA is to provide strengthen to the concrete and to decrease the cost of construction. Kartini et al. said that RHA is a economical cementing material since it is waste product having high silica content, high porosity, light weight with high surface area ${ }^{2}$. Khassaf et al. determine that workability of fresh concrete fall with the increase of RHA content ${ }^{3}$. Marthong examine that the stability of RHA cementitious paste decreased as compared to OPC cement paste. This shows reduction in water demand and should reduce shrinkage ${ }^{4}$. Ephraim et al. conclude that use of Rice husk ash in construction works will decrease the environmental pollution, strengthen the concrete quality and optimize the cost of concrete as well as resolving the problem of agricultural waste management ${ }^{5}$.

\subsection{Rice Husk Ash (RHA)}

RHA is a consequence of the cultivated industry which contains great amount of silicon dioxide ( $\mathrm{SiO} 2)$. About 70 million tons of rice husk ash is produced worldwide per year. During shattering of rice process about 78 percent of remaining weight is extracted as rice. Remaining 22 percent of the weight is received as husk. It contains about 75 percent of organic content and the remaining 25 percent of husk is transformed into ash during the burning process, is identified as rice husk ash. Every one thousand kilograms of material, about two hundred twenty kilograms (22 percent) of husk is formed and when husk is burnt it gives 55 kilograms (25 percent) of Rice Husk Ash. The super pozzolona are used to make high strength concrete mix. There is increasing demand of silica to make high performance and high strengthen concrete. Rice Husk Ash concrete gives a durable and good structural concrete for both short term and long term considerations ${ }^{6}$. Dabai et al. conclude that the chemical study prepared on rice husk ash directed high quantity of silica for RHA with good workability ${ }^{?}$.

\section{Experimental Program}

\subsection{Materials}

\subsubsection{Cement}

In the present study OPC 43 grade cement ${ }^{8}$ for design mix. The various properties of cement are examined i.e. compressive strength after 3 days, 7 days and 28 days, specific gravity, consistency and initial and final setting of cement as shown in Table 1.

Table 1. Properties of OPC 43 grade cement

\begin{tabular}{|l|l|c|}
\hline S.no. & Characteristics & $\begin{array}{c}\text { Value obtained } \\
\text { Experimentally }\end{array}$ \\
\hline $\mathbf{1 .}$ & Specific Gravity & 3.13 \\
\hline $\mathbf{2 .}$ & Standard Consistency & $33 \%$ \\
\hline \multirow{3}{*}{} & Initial Setting Time & 47 minutes \\
\hline \multirow{2}{*}{$\mathbf{5 .}$} & Final Setting Time & 252 minutes \\
\hline \multirow{3}{*}{} & Compressive Strength & \\
\cline { 2 - 3 } & 3 days & $27.3 \mathrm{~N} / \mathrm{mm}^{2}$ \\
\cline { 2 - 3 } & 7 days & $35.6 \mathrm{~N} / \mathrm{mm}^{2}$ \\
\cline { 2 - 3 } & 28 days & $47.4 \mathrm{~N} / \mathrm{mm}^{2}$ \\
\hline
\end{tabular}

\subsubsection{Coarse Aggregate}

Coarse aggregate used in experimental are combination of two nearby available stone of $20 \mathrm{~mm}$ and $10 \mathrm{~mm}$ size in 70:30 divisions respectively. The specific gravity examined for $20 \mathrm{~mm}$ and $10 \mathrm{~mm}$ aggregate is 2.73 and 2.71 respectively.

\subsubsection{Fine Aggregate}

Fine aggregate used for experimental work is of Zone II examined by IS: $383-1970^{\circ}$. The specific gravity examined is 2.49 .

\subsubsection{Rice Husk Ash (RHA)}

RHA used for experimentation is collected from Rice Sheller and processed to size less than 45 microns to be replaced with cement. The specific gravity found to be 2.3 .

\subsection{Mix Design for Concrete}

The main objective of experimental work is to investigate compressive strength, split tensile strength and flexural strength of concrete. M40 grade of concrete is used to examine the mechanical properties of concrete with 0.40 water -cement ratio. The mix design was prepared to examine the properties of concrete as per IS 10262-1982 ${ }^{10}$. The mix proportion of concrete as given in Table 2. 
Table 2. Mix Proportion for per cubic meter concrete

\begin{tabular}{|l|c|c|c|c|c|c|c|c|c|}
\hline \multirow{2}{*}{ S. no } & Mix & \multicolumn{7}{|c|}{$\begin{array}{c}\text { Mix proportion (C:FA:CAI:CAII) } \\
(1: 1.828: 1.936: 0.83)\end{array}$} \\
\cline { 3 - 11 } & & $\begin{array}{c}\text { RHA } \\
\%\end{array}$ & $\begin{array}{c}\text { RHA } \\
(\mathrm{Kg} / \mathrm{m} 3)\end{array}$ & $\begin{array}{c}\text { Cement } \\
(\mathrm{Kg} / \mathrm{m} 3)\end{array}$ & w/b ratio & $\begin{array}{c}\text { F.A } \\
(\mathrm{Kg} / \mathrm{m} 3)\end{array}$ & $\begin{array}{c}\text { C.AI(20) } \\
(\mathrm{Kg} / \mathrm{m} 3)\end{array}$ & $\begin{array}{c}\text { C.AII(10) } \\
(\mathrm{Kg} / \mathrm{m} 3)\end{array}$ & $\begin{array}{c}\text { S.P. } \\
\%\end{array}$ \\
\hline $\mathbf{1}$ & CM & 0 & - & 390 & 0.4 & 713 & 755.30 & 323.70 & 0.5 \\
\hline $\mathbf{2}$ & M-RHA5 & 5 & 19.5 & 370.5 & 0.4 & 713 & 755.30 & 323.70 & 0.5 \\
\hline $\mathbf{3}$ & M-RHA10 & 10 & 39 & 351 & 0.4 & 713 & 755.30 & 323.70 & 1 \\
\hline $\mathbf{4}$ & M-RHA15 & 15 & 58.5 & 331.5 & 0.4 & 713 & 755.30 & 323.70 & 1 \\
\hline $\mathbf{5}$ & M-RHA20 & 20 & 78 & 312 & 0.4 & 713 & 755.30 & 323.70 & 1 \\
\hline
\end{tabular}

C: Cement, F.A.: Fine Aggregate, C.AI (20): Coarse Aggregate of 20 mm,

C.AII (10): Coarse aggregate of $10 \mathrm{~mm}$, S.P: Super plasticizer

RHA: Rice Husk Ash CM: Control Mix

\section{Test Results and Discussion}

\subsection{Compressive Strength}

The $150 \mathrm{~mm}$ cube mould are used for testing the compressive strength after 7 days and 28 days as per IS: 516-195911. Specimens has been made for control mix and compared with different percentages replacement of cement with RHA i.e. for $5 \%, 10 \%, 15 \%$ and $20 \%$ by weight. Specimens were tested after seven days and twenty days age of curing and average results of are shown in Figure 1.

The compressive strength examined for different percentages of RHA with replacement of cement (by weight) i.e. for $5 \%, 10 \%, 15 \%$ and $20 \%$. Compressive strength for $5 \%$ replacement i.e. M-RHA5 increased by $2.1 \%$ as compared with control mix after 28 days testing and for

Average Compressive Strength after 7 days and 28 days in $\mathrm{N} / \mathrm{mm}^{2}$

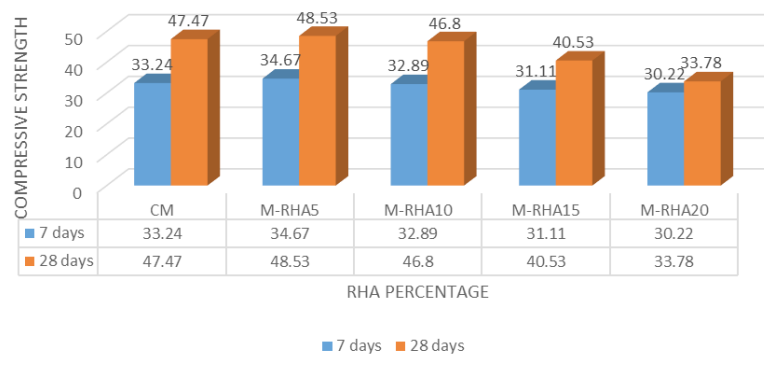

Figure 1. Average compressive strength after 7 days and 28 days in $\mathrm{N} / \mathrm{mm}^{2}$.
$10 \%$ replacement i.e. M-RHA10 decreased by $1.4 \%$ as compared with control mix after 28 days testing and it decreases for M-RHA15 and M-RHA20 mixes by $14.6 \%$ and $28.8 \%$ respectively. RHA is pozzolonic material contain high silica have same property like cement. RHA when mixed with concrete mix, due to their fineness it will make good bond with other material particles in concrete mix at some content of RHA and it will increase the compressive strength of concrete due to their pozzolonic effect but after further addition of RHA strength start decreasing because it will effect heat of hydration of cement which will effect the compressive strength of concrete mix. As discuss in Figure 1, after addition of $15 \%$ and $20 \%$ replacement of RHA strength decreases suddenly. So range of $5-10 \%$ of RHA is optimum content for concrete mix for compressive strength of concrete because at $5 \%$ replacement there is slight rise in compressive strength after 28 days and at $10 \%$ replacement slight decrease in strength as compared with control mix. So use of M-RHA10 will reduce the cost of construction as compared to M-RHA5.

\subsection{Split Tensile Strength}

The $300 \mathrm{~mm} \times 150 \mathrm{~mm}$ cylinders $\mathrm{s}^{12}$ were used for testing the split tensile strength after 7 days and 28 days. Specimens have been made for control mix and compared with different percentages replacement of cement with RHA i.e. for $5 \%, 10 \%, 15 \%$ and $20 \%$. The split tensile strength of all the mixes was determined at the age of 7 days and 28 days for various replacement levels of RHA in concrete mix and discussed in Figure 2. 


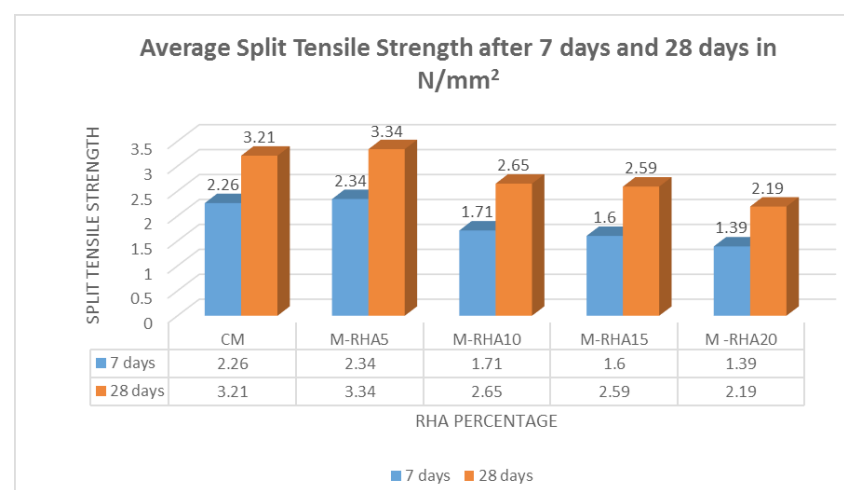

Figure 2. Average Split tensile Strength after 7 days and 28 days in $\mathrm{N} / \mathrm{mm}^{2}$.

The split tensile strength results of individual concrete mix are also shown graphically. Split tensile strength also increases after 5\% replacement for M-RHA5 i.e. increased by $3.9 \%$ and after $10 \%$ replacement it decrease by $17.5 \%$ and further decreasing for $15 \%$ and $20 \%$ replacement by $19.3 \%$ and $31.7 \%$ respectively as compared with RHA. The maximum values of split tensile strength of concrete with addition of rice husk ash at $5 \%$ addition which is slightly higher than control mix. At $10 \%$ addition of rice husk ash decrease in strength. For strength purpose $5 \%$ is acceptable for split tensile strength but for cost reduction $10 \%$ is also acceptable due to less decrease in strength after 28 days.

\subsection{Flexural Strength}

The beam specimens $100 \mathrm{~mm} \times 100 \mathrm{~mm} \times 500 \mathrm{~mm}$ were used for testing the flexural strength after seven days and twenty-eight days. Specimens has been made for control mix and compared with different percentages replacement of cement with RHA i.e. for $5 \%, 10 \%, 15 \%$ and $20 \%$. The flexural strength after seven days and twenty days discussed in given Figure 3.

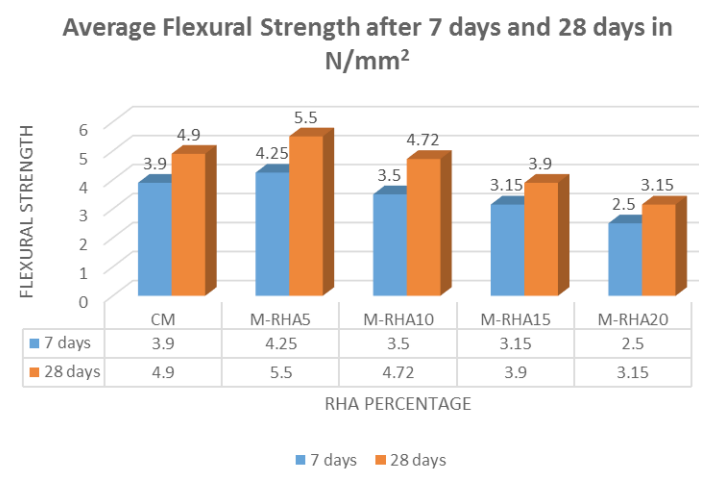

Figure 3. Flexural Strength after 7 days and 28 days in $\mathrm{N} / \mathrm{mm}^{2}$.
As discussed in Figure 3, when RHA reinforced concrete and composite beams are loaded in pure bending, then the tensile strains develop. The load at first crack would increase with respect to rice husk ash reinforced concrete due to crack arresting mechanism of the closely spaced fibers. After the concrete matrix cracks, the fibers continue to take higher load which is provided. For M-RHA5, flexure strength increases by 12 $\%$ and beyond that it starts decreasing. For M-RHA 10 decreases by $3.6 \%$ due to effect on heat of hydration and further decreasing for M-RHA15 and M-RHA20 is $20.4 \%$ and $35.7 \%$ respectively. So M-RHA10 is adopted as optimum content as there is slight decrease in strength as if compared with M-RHA5 and control mix.

\section{Conclusions}

From these experiments work, the conclusion can be drawn:

- RHA is environment friendly and easily available and so it will give benefit if used for construction purpose.

- Concrete mix with 10 percent RHA as replacement of cement is the optimum level as it has been observed to show a significant increase in compressive strength at 28 days when compared with control mix.

- The split tensile strength also tends to increase with increase percentages of RHA up to 5\% mix but slightly decrease after $10 \%$ replacement but is more than control mix.

- On increasing the percentage replacement of cement with RHA beyond $5 \%$, there is a reduction in the tensile strength value. So 5\% RHA replacement is optimum for split tensile strength.

- Maximum flexure strength of incorporating RHA is achieved for 5\% RHA replacement but at $10 \%$ RHA replacement strength decrease slightly from control mix strength.

- Optimum content for compressive strength and flexure strength is $10 \%$ replacement with cement with rice husk ash after that strength start decreasing suddenly, for split tensile strength optimum content is $5 \%$ and after that is start decreasing with increase of RHA content. 


\section{Reference}

1. Kulkarni MS, Mirgal PG, Bodhale PP, Tande SN. Effect of rice husk ash on properties of concrete. Journal of Civil Engineering and Environmental Technology. 2014; 1(1):26-9.

2. Kartini, K, Mahmud HB, Hamidah MS. Strength properties of Grade 30 rice husk ash concrete. 31st Conference on Our World in Concrete and Structures; 2006.

3. Khassaf SI, Jasim AT, Mahdi FK. Investigation on the properties of concrete containing rice husk ash to reduction the seepage in canals. International Journal of Scientific Technology Research. 2014; 3:348-54.

4. Marthong C. Effect of Rice Husk Ash (RHA) as partial replacement of cement on concrete properties. International Journal of Engineering Research and Technology. 2012 Aug; 1(6).

5. Ephraim M, Akeke GA, Ukpata JO. Compressive strength of concrete with RHA as partial replacement of ordinary Portland cement. Scholarly Journal of Engineering Research. 2012; 1(2):32-6.
6. Akeke GA, Ephraim M, Akobo IZS, Ukpata JO. Structural properties of rice husk ash concrete. International Journal of Advances in Engineering Sciences and Applied Mathematics. 2013; 3(2):8269.

7. Dabai M, Muhammad C, Bagudo B, Musa A. Studies on the Effect of Rice Husk Ash as Cement Admixture. Nigerian Journal of Basic and Applied Sciences. 2009; 17(2): 252-6.

8. IS: 8112-1989: Specification for 43 Grade Ordinary Portland cement, Bureau of Indian Standard, New Delhi; 2005.

9. IS: 383-1970: Specification for Coarse and Fine Aggregates from Natural Sources for Concrete, Bureau of Indian Standard, New Delhi; 1970

10. IS: 10262-1982: Recommended guidelines for concrete mix design, Bureau of Indian Standard, New Delhi; 2004

11. IS: 516-1959 Methods of tests for strength of concrete, Bureau of Indian Standard, New Delhi; 2004.

12. IS: 5816-1999: Methods of test for Splitting Tensile Strength of Concrete, Bureau of Indian Standard, and New Delhi;1999. 